movement and forces. He does more; he provides glimpses of many different paths leading off his main theme in many different directions; there will be some, at least, who will be stimulated to follow these paths and see where they lead.

The illustrations are good and some of the photographs technically excellent. I found a particularly happy liaison between text and pictures. One rarely has to look forward or back to find the appropriate illustration, and what more convincing demonstration could one wish of the powerful force exerted by a swimming fish than to turn the page and find the photograph of the swordfish which smashed a boat!

The whole book, by its use of familiar things, drives home the application of natural laws, and one is left wishing that the next step - the mechanism of the control by the living creature of these laws in relation to itself-might be equally lucidly set out. Perhaps Professor Gray will oblige!

B. M. J.

African Insect Liff. By S. H. Skaife. Longmans Green and Co., 1954. £3 $3 s$.

This book, which is really a textbook of entomology with special reference to African insects, cannot fail to be of considerable use and interest to amateur entomologists and agriculturists, particularly those resident in the southern half of the African continent.

It is divided into twenty-two chapters, each dealing with an Order, starting with the primitive insects such as the bristletails and the spring-tails, and ending, in chapter twenty-two, with ants. Structure, life-histories, habits and habitats are adequately described throughout and although the reader will probably become aware of the author's particular liking for the social insects, especially the termites and ants, all the Orders have been faithfully dealt with. In the chapters dealing with the social insects, methods of maintaining alive small colonies and brood chambers are described and figured, enabling the life-histories to be watched in the comfort of a study or the seclusion of a garden. Solitary bees can be induced to occupy glass tubes while with cork lino and ply wood excellent observation nests for termites and ants can easily and cheaply be constructed.

These details should encourage would-be entomologists of all ages to observe the living insect as well as or instead of capturing it for mounting in a cabinet. 
Gardeners and agriculturists with access to this book will be helped to recognize the many insects which are injurious to plant life in either their larval or adult stages.

At the end of each chapter is a brief synopsis of the Families embraced in the Order concerned, while terminating the book is a general index. There are many black and white illustrations in the text, one to almost every page, and all are very good. The seventy-five plates, however, cannot be praised, for while the five in colour are quite good, the majority of the halftones are of poor quality - a pity, especially where the subjects are of particular interest. 'There is a misprint in the generic name of the red locust, depicted on colour plate II : it should be Nomadacris not Normadcris. The print is clear and the binding serviceable, with the title boldly showing on the spinea good feature when a volume is being looked for on a Jibrary shelf.

\section{C. B.}

Gold Dish and Kava Bowl. By John A. Fraser. J. M. Dent and Sons. 18s.

When one reads of people searching for gold there come to mind the mad days of the Klondyke, and the unscrupulous characters and violent crimes usually associated with a gold rush. In Gold Dish and Kava Bowl we have a very different picture. Here we meet men who, like their fathers before them, have spent their lives quietly prospecting and mining for gold, often with little material gain, but with a deep regard for their homeland and their way of life.

John Fraser unfortunately died in 1946, and Terence O'Brien has been responsible for editing the original manuscript and selecting the photographs. The author tells us first of his childhood home at Wandiligong in the south-eastern corner of Australia. He was always a miner at heart, and he soon acquired an observant eye for the flowers and trees and structure of his country. He tells us pleasantly and easily a good deal about the origin of gold reefs and beds, and the methods used by prospectors and miners in their laborious and often unrewarding task.

Most of the scene, however, is set in Fiji, where he spent several years prospecting on Viti Levu, the largest island of the group. In the course of his work Fraser travelled to every part of the island. There emerges a very happy picture of the vigorous, lighthearted Fijians, or Kai Vitis as they describe themselves, and their customs, seen through the eyes of a man who had 